\title{
Improved AODV for engineering applications in Wireless Ad Hoc Network
}

\author{
Luan Hui, Tan Xiaoyun, Zhang Haifeng" Wang Wei \\ MEMS Center, Harbin Institute of Technology, Harbin, China \\ moonzhf@163.com
}

\begin{abstract}
The wireless mesh network(WMN) is a wireless network using multi-hop communication. Wireless mesh network node used in the engineering applications has many characters. Such as the node has limited energy, the hierarchical topology is obvious, the message is used to communicate from the node outside to the node inside. AODV is a typical standard by actual demands. This paper describes a J-AODV standard which is based on AODV standard. It considers node energy, near-by nodes and delays to choose route path which can make the average delay, network throughput and consumptions optimized most.
\end{abstract}

Keywords: AODV, WMN J-AODV

\section{Introduction}

AS a typical standard by actual demands, AODV network is widely used in small $\mathrm{WMN}^{[1]}$. It contains four formats which are RREQ, RREP, RERR and RREPACK. The processes mainly contains searching process and maintaining process. $\mathrm{AODV}^{[2]}$ can provide a fast adaptive to active state of link path with a low cost of process and store. However, as a universal standard, lots of limitations still exist in engineering application. Such as battlefield surveillance, electronic conference and emergency response ${ }^{[3]}$. This paper provides an engineering application oriented J-AODV standard. The first section describes the characters of WMN and topology structures in engineering application. The second section describes the limitation of AODV standard in engineering application. The third section describes the design of J-AODV and calculation of parameters. The last section is the $\mathrm{NS}^{[4]}$ simulation and analysis of experiment results.

\section{Characters of $\mathrm{WMN}$ in Engineering Application}

\subsection{Limited node energy}

Wireless network node is used mostly in the outdoor environment which lacks construction support and is hard wiring. Each node holds limited energy, and if some of them run out, the whole net function will be effected.

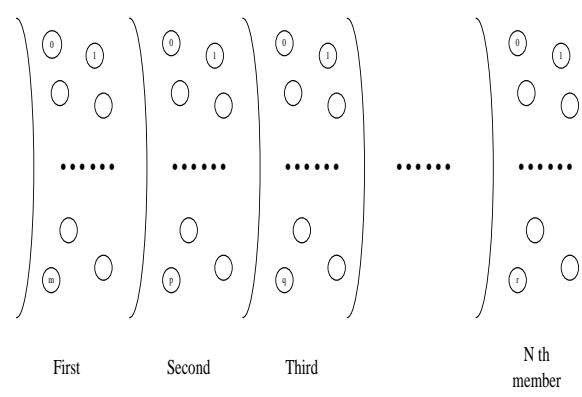

Fig. 1: a typical WMN topology structure.

\subsection{Obvious level topology}

Figure 1 is a typical WMN topology structure. Node 0 is the central server which can be considered to have 
unlimited power. Most of requests of net connection is based on node 0 which can be seen as source node or destination node. N10 N1m is the first level nodes. $\mathrm{N}$ is the $\mathrm{n}$-th level node. Mostly, node 0 will play a role as administrator or watcher. This paper makes the relatively front node as front stage node, relatively secondary one as secondary node. For example, $\mathrm{N} 1$ is the front node of $\mathrm{N} 2$ and $\mathrm{N} 2$ is the secondary node of N1. Node 0 is the central node.

\subsection{Information comes together from outside node to central node}

Inside node transmit information of itself and secondary node. Inside node makes the bottleneck of secondary stage in this level .

\section{J-AODV Design}

The route maintaining section is reserved in the AODV standard. The function will be extended from the former route searching process. The extended section consists of two parts. The first section is RREQ sending function, in this part, the data around battery energy node will be added to the RREQ where the reserved 9 bits is used. The second section is callback function of receiving RREQ.

Slack time: the time from the first RREQ received to next RREQ received by the same destination node. If the RREQ exceeds the time, it will be abandoned.

Willing parameter: This parameter consists of node energy and node number around. The willing value can be judged by former stage node.

Figure 2 shows the process of program.

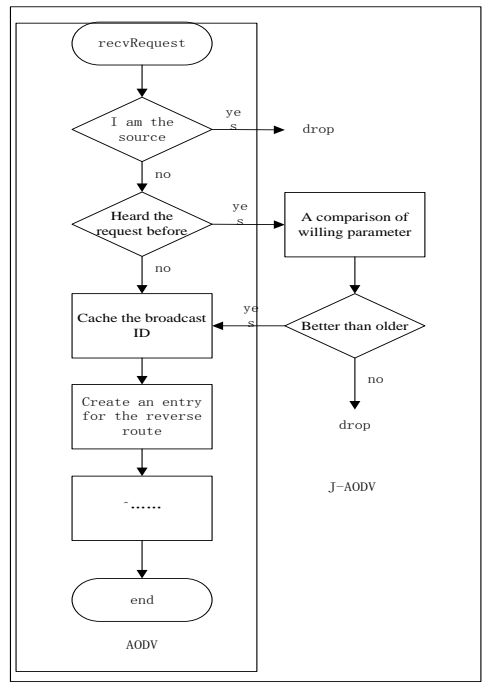

Fig. 2: the process of AODV and J-AODV.

The whole scheme can be considered as follows: The RREQ will not be threw when it belongs to the same destination node and willing value will be judged whether higher that that of former stage node. If a node has higher energy but fewer around nodes, it will have larger willing value and next node will update it as reverse route node.

The choice of willing parameter need to consider whether it could reflect the true performance of network. A simple willing parameter is the number of secondary nodes which can infer the average delay between levels, energy cost speed of nodes and max throughput between levels.

\section{Analysis of NS Simulation Result}

The figure below shows topology structure:

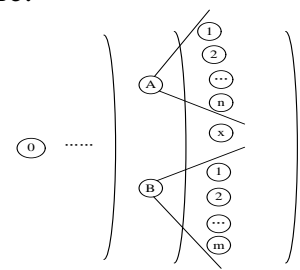

Fig. 3: the topology of simulation 
Set Max number of packages of network adapter as 50, wireless transmit speed as $200 \mathrm{Mb} / \mathrm{s}$.

Mode: $\mathrm{n}=1, \mathrm{~m}=0 ; \mathrm{n}=1, \mathrm{~m}=1 ; \mathrm{n}=2$, $\mathrm{m}=1 ; \mathrm{n}=3, \mathrm{~m}=1 ; \mathrm{n}=3, \mathrm{~m}=2 ; \mathrm{n}=4$, $\mathrm{m}=1$.

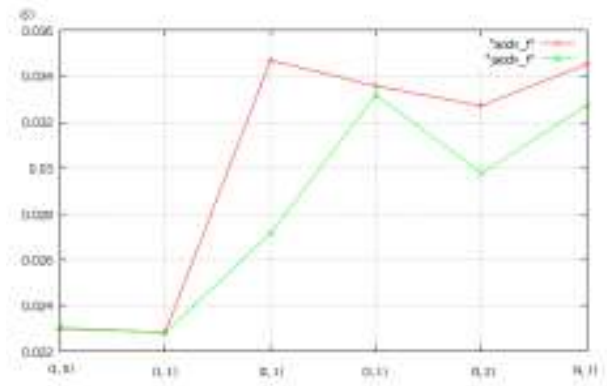

Fig. 4: delay per package

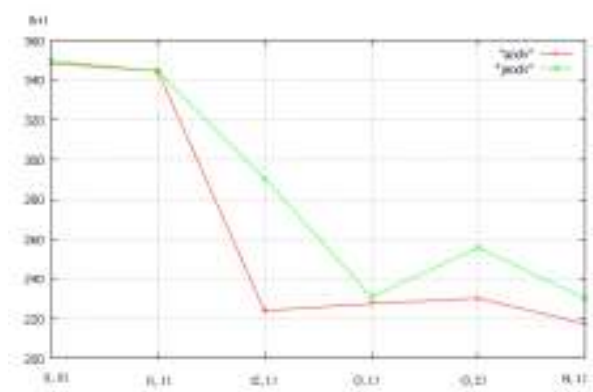

Fig. 5: throughput

From the simulation result, J-AODV is better than AODV standard in throughput and delay per package.

The searching process of AODV route contains route request of source node, reverse route set up, transmit and process of middle node pair route, route response of destination node and transmit of route response.

AODV chooses path by single-path minimum delay significant principle. When a node receives RPEQ first, it will store the broadcast ID and destination address. When it receives a RREQ from a different node with the same destination node, it will lose the later RREQ. Therefore, a node will choose the last jump node with minimum path delay as the reverse route node in the AODV standard. When simply considering the nodes between levels and ignoring the delay of front stage node and source node, this node will consider the nearest front node as transmit node. Figure 6 shows the detail.

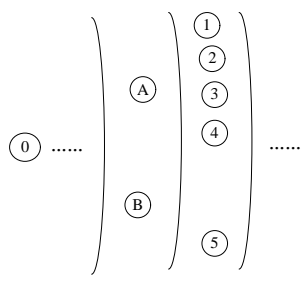

Fig. 6: A typical case.

Consider middle node 0 to node $\mathrm{A}$ has the same delay with it to node B. Node A can only communicate with node 2 , node 3 , node 4 and node 5, with delay $D_{1}, D_{2}, D_{3}, D_{A 4}$. B can only communicate with node 4 and node 5 with delay $D_{B 4}, D_{5} \quad \cdot \quad D_{1}+D_{2}+D_{3}+D_{A 4}>D_{5}$, $D_{1}+D_{2}+D_{3}>D_{5}+D_{B 4}$. There would be no difference when node $\mathrm{A}$ and node $\mathrm{B}$ communicate with lower level. In this way, when node 4 communicates with node 0 , it will choose $\mathrm{A}$ as transmit node. The distance between node 4 and node A is less than that between node 4 and node B. Therefore, 4->A->.....->0. Node 4 will choose $\mathrm{A}$ as transmit node according to single path delay minimum principle. However, two problems occur.

First, as node A is responsible for the transmit of node 1, 2, 3,4 in the next level, this process will cost more energy than the transmit from node 5 to node 1 which node is responsible for. If node A's energy runs out, the whole net will not be complete. Therefore, when node 1, 2, 3 already choose node A as transmit node, node 4 should choose node $\mathrm{B}$ as transmit node. Node A would not be tired for overload of transmitting more node data. Node B is idle although treated as 
transmit. In this way, it can be better balanced.

Second. Although the single path from node 4 to node 0 makes the minimum delay, it's not the average delay minimum path of whole network.

If node $A$ is responsible for the transmit of node 1, 2, 3, 4, when any one of them communicates with $\mathrm{A}$, the others will be in holding state. If node 1, 2, 3, 4 send data to node 0 at the same time, the average delay should be as:

$$
\overline{D_{A(1,2,3,4)}}=\frac{D_{1}+D_{2}+D_{3}+D_{4}}{4}
$$

$D_{x}$ is the delay time from node $\mathrm{X}$ to node $\mathrm{A}$. The total communicating time between $1,2,3,4$ to $\mathrm{A}$ is the sum of every single node to node A. Average time can be calculated when it divided by 4.

$$
\overline{D_{B(5)}}=D_{5}
$$

During $\max \left(4 * \overline{D_{A(1,2,3,4)}}, \overline{D_{B(5)}}\right)$, five nodes can finish the communication with former stage nodes, so the average delay is

$$
\bar{D}=\frac{\max \left(4 * \overline{D_{A(1,2,3,4)}}, \overline{D_{B(5)}}\right)}{4+1}=\frac{D_{1}+D_{2}+D_{3}+D_{4}}{5}
$$

If node 4 chooses node $B$ as the transmit node, the average delay is

$$
\overline{D^{\prime}}=\frac{D_{1}+D_{2}+D_{3}}{5} .
$$

So choosing node $\mathrm{B}$ as transmit node can optimize average delay than choosing node $\mathrm{A}$ for node 4.

As noted, the number of nodes around a node can affect the stability. J-AODV choose node $\mathrm{B}$ as transmit node. So the $\mathrm{J}$ AODV is better than AODV.

\section{Conclusion}

In this paper, we describe a J-AODV standard which is based on AODV standard. And we choose the number of secondary nodes as a simple willing parameter to prove this method is feasible. Simulation analysis using NS2 platform shows J-AODV is useful to make the average delay, network throughput and consumptions optimized most in the engineering applications.

\section{Acknowledgement}

The authors would like to acknowledge the financial support from the national high technology research and development program of china (Grant No. SS 2012AA062902), Major Science and Technology Program for Water Pollution Control and Treatment (Grant No. 2012ZX07201003-01), Key Science and Technology Project of Harbin (Grant No. 2011AA1CG003).

\section{References}

[1] D. B. Johnson, "Routing in Ad Hoc Networks of Mobile Hosts, "Proceedings of Workshop on Mobile Computing Systems and Applications ,pp.158-163,Dec.1994.

[2] C. E. Perkins, E. M. Rover, "Ad-hoc on-demand distance vector routing," Proceedings of Mobile computing Systems and Application '99 (WMCSA '99),pp.90-100,Feb.1999.

[3] M.Frodigh, P.Johansson, and P.Larsson, "Wireless ad hoc networking : the art of networking without a network, "Erisson Review,pp.248-263,2000.

[4] K.Fall,K.Varadhan.(1998,October.21) ,"ns Notes and Documentation." Available:

http://www.monarch.cs.rice.edu/ftp/m onarch/wireless-sim/nsDoc.pdf 